
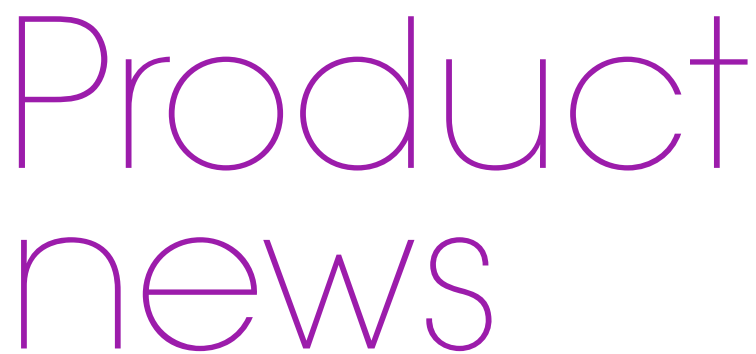

\section{CHEERS TO 20 YEARS}

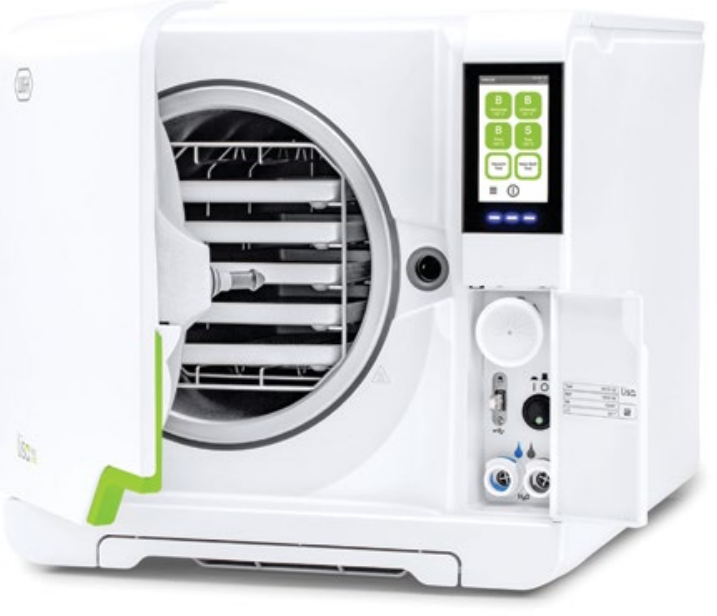

joined the W\&H family of decontamination solutions in 1999 and has since been sold more than 60,000 times in 80 countries across the world.

Lisa not only enables you to optimise your workflow and output at a glance with EliSense, but also ensures extended documentation and full traceability down to a single instrument or kit with EliTrace.

Clinicians can also use the Lisa Mobile App for real-time remote monitoring of up to four sterilisers using a smartphone or tablet. For further details, contact W\&H today.

Manufacturer $\mathrm{W} \& \mathrm{H}$ is raising a glass to celebrate the 20th anniversary of the Lisa steriliser. This incredible system

\section{CORONAVIRUS INFECTIOUS WASTE MANAGEMENT}

Supporting healthcare facilities across the UK, including urgent care dental practices, Initial Medical is offering a collection and disposal service for waste contaminated or potentially contaminated with Coronavirus.

According to government guidance, any waste generated from the treatment of known or suspected Coronavirus patients must be disposed of as Category B waste. That means orange on the Department of Health's best practice colour code for waste disposal, including the relevant bags, rigid containers and sharps containers.

Available to help customers stay compliant in any situation, Initial Medical now offers your go-to solution for safe collection and disposal of any waste possibly contaminated with Coronavirus. Give the team a call today for more information.

As a producer of any controlled waste in the UK, it is your legal responsibility under your Duty of Care to ensure the correct and proper management of the waste you generate. In order to support your waste disposal practices, Initial Medical's unique e-learning platform 'myLearning' provides a flexible solution to waste management and infection control training, and is accessible 24/7.

For further information visit www.initial. co.uk/medical or call 08708504045 .

\section{VAT FREE PPE}

The Government has announced that all PPE equipment purchased between 1 May and 31 July 2020 will be VAT free.

Trycare supply an extensive range of PPE products to meet the individual requirements of every member of the practice team. This includes an extensive range of disposable drapes and gowns.

Trycare's disposable sterile surgical gowns and patient drapes are made of a special man-made material called SMS, which is a fluid repellent breathable material to ensure the comfort of the wearer during the operative procedure.

SMS stands for spunbond/meltblown/ spunbond and is a special material which does not have a polythene layer as this would make it too warm to wear for long periods.

Trycare offer their drapes, gowns and ancillary items individually, in bulk packs and in a variety of off-the-shelf packs designed to meet the requirements of different clinical procedures. The latter include their most popular Surgikit as well as their Surgitwo, Endokit, Minimal Implant Kit, Dental Apicectomy Kit, Universal Drape Kit and Economy Drape Kit. For details of the contents and prices visit the Trycare website www.trycare. co.uk or page 61 of their 2019 Surgical Essentials Catalogue.

Should none of the above contain exactly what you want then Trycare can supply customised drape kits designed to meet the individual needs of the practice.

For more information about Trycare's comprehensive VAT free PPE range, including drapes and gowns, contact your local Trycare Representative, call 01274 885544 or visit www.trycare.co.uk. 